\title{
Answer to the Letter to the Editor of I. Aprile et al. concerning "Health-related quality of life in patients with adolescent idiopathic scoliosis after treatment: short-term effects after brace or surgical treatment" (by Bunge EM et al. Eur Spine J 16: 83-89, 2007)
}

\author{
Eveline M. Bunge $\cdot$ Harry J. de Koning
}

Accepted: 8 July 2007/Published online: 22 August 2007

(C) Springer-Verlag 2007

Dear Editor,

We appreciate the effort of Aprile and colleagues on the evaluation of long-term effects of surgery or conservative treatment on health-related quality of life in patients with scoliosis. We agree that this is an important topic that needs further evaluation.

Probably due to the time period between completing treatment and follow-up, the authors had trouble reaching more than half, namely $65 \%$ of the patients who met the inclusion criteria; another $13(13 \%)$ patients refused to participate. Unfortunately, only 21 patients of the initial population participated, which may have led to biased results.

Aprile did not find statistically significant differences in HRQoL between the CONS patients and the SURG patients, but that could very well be attributable to the small numbers in their treatment groups. For instance, on the Visual Analogue Scale for pain, the difference is not statistically significant, but the CONS group scored 1.7 points higher on a 10 point scale. The CONS group scored 6.9 points which can be interpreted as a satisfactory mark, while the SURG group scored 5.2 points which can be interpreted as an unsatisfactory mark. The scales "SF Social Functioning" and "SF Role Emotional" show a similar trend. On these scales, the conservative group tend to score better, but again, numbers are too small for conclusive evidence.

Danielsson et al. [1] also studied long-term HRQoL in scoliosis patients using the SF36. SF36 scores tend to be higher (i.e., better) in the study by Danielsson than in the study by Aprile.

Further research on this topic is still needed. Preferably, a large cohort of patients with idiopathic scoliosis should prospectively be followed from the start of treatment (brace, watchful waiting, surgery) till long-term follow-up of 20-50 years.

\section{Reference}

1. Danielsson AJ, Wiklund I, Pehrsson K, Nachemsom AL (2001) Health-related quality of life in patients with adolescent idiopathic scoliosis: a matched follow-up at least 20 years after treatment with brace or surgery. Eur Spine J 10:278-288
This author's reply refers to the article http://dx.doi.org/10.1007/s00586-007-0461-4.

E. M. Bunge $(\varangle) \cdot$ H. J. de Koning

Department of Public Health, Erasmus MC,

University Medical Center Rotterdam,

P. O. Box 2040, 3000 CA, Rotterdam,

The Netherlands

e-mail: e.bunge@erasmusmc.nl 